\title{
WORKSHOP PEMANFAATAN MEDIA PEMBELAJARAN GEOGEBRA UNTUK MENINGKATKAN KOMPETENSI GURU MATEMATIKA
}

\author{
Nur Sahara1), Masdelima Azizah Sormin"1), Lisna Agustina1) \\ ${ }^{1)}$ Pendidikan Matematika, FKIP Universitas Muhammadiyah Tapanuli Selatan, \\ saharanur.ns@gmail.com
}

DOI : 10.31604/jpm.v2i1.40-44

\begin{abstract}
The utilization of instructional media in mathematics become creativity that should be possessed by the teachers of mathematics because with the mastery and use of the media expected students feel co-owns the lessons conveyed by the teacher. Currently, computer programs in learning mathematics is an inevitability. One of the computer programs that can be utilized in the study of mathematics is GeoGebra. Assumption students taking action against difficult math will be lost along with the skill they will have with the utilization of GeoGebra. This article presents a description of how servants apply GeoGebra in every pembelaran the math. The target of this activity is the teachers of mathematics in South Tapanuli. The number of workshop participants as much as 16 people. The place of execution of the activities implemented in SMA Negeri 1 Sipirok. Implementation of the method used is the method of experimental and mentoring. The existence of this activity was able to increase the motivation of teachers MGMP South Tapanuli abreast in Mathematics Teaching and learning activities.
\end{abstract}

Keywords: GeoGebra, Mathematics

\begin{abstract}
Abstrak
Pemanfaatan media pembelajaran dalam matematika tentunya menjadi sebuah kreativitas yang harus dimiliki oleh guru matematika sebab dengan penguasaan dan penggunaan media tersebut diharapkan siswa merasa ikut memiliki pelajaran yang disampaikan oleh guru. Saat ini, program computer dalam pembelajaran matematika merupakan keniscayaan. Salah satu program computer yang dapat dimanfaatkan dalam pembelajaran matematika adalah GeoGebra. Anggapan siswa tehadap matematika yang sulit akan hilang seiring dengan skill yang akan mereka miliki dengan pemanfaatan GeoGebra ini. Artikel ini menyajikan uraian bagaimana pengabdi menerapkan GeoGebra dalam setiap pembelaran matematika. Target kegiatan ini adalah guru-guru matematika di Tapanuli Selatan. Jumlah peserta workshop sebanyak 16 orang. Tempat pelaksanaan kegiatan dilaksanakan di SMA Negeri 1 Sipirok. Metode pelaksanaan yang digunakan adalah metode eksperimental dan pendampingan. Dengan adanya kegiatan ini mampu meningkatkan motivasi guru-guru MGMP Matematika Tapanuli Selatan dalam mengikuti kegiatan belajar mengajar.
\end{abstract}

Kata Kunci : GeoGebra, Matematika

MARTABE : Jurnal Pengabdian Masyarakat $\mid 40$ 


\section{PENDAHULUAN}

Kegiatan
pengabdian
masyarakat merupakan salah satu
kegiatan dalam tri dharma perguruan
tinggi yang harus dilakukan dan
direncanakan oleh dosen sebagai pelaku
pendidikan yang memiliki tugas
professional dalam tri dharma
perguruan tinggi. Kegiatan pengabdian
pada masyarakat ini sebagai sarana
kontribusi pada masyarakat sesuai
dengan bidang keilmuan yang
dikembangkan.

Pendidikan Matematika sebagai salah satu program pendidikan yang sangat relevan dengan kebutuhan masyarakat. Masyarakat yang dimaksud disini tentu saja masyarakat yang menjadi pengguna matematika. Komunitas guru sekolah menengah adalah masyarakat terdekat yang dapat menikmati kegiatan pengabdian ini.

Paradigma masyarakat terhadap matematika sebagai ilmu yang sulit dan tidak menarik kiranya masih actual dan hangat di kalangan masyarakat saat ini. Evaluasi terhadap pembelajaran ini dinilai masih sangat jauh dari harapan yang sesungguhnya terhadap relevansi yang ada sehingga hal ini menjadi sebuah indikator sulitnya matematika di kalangan siswa. Agar matematika itu menjadi lebih mudah dan menarik tentu banyak hal yang sudah dilakukan oleh para guru dengan berbagai metode dan strategi pembelajaran yang berkembang saat ini. Tentu dalam hal ini guru dituntut memiliki kreativitas untuk membuat matematika menjadi sebuah ilmu yang realistic bagi siswa dari sifat ke abstrakannya.

Seiring dengan berkembangnya pemanfaatan computer dalam berbagai bidang maka kebutuhan sumber daya manusia (SDM) dalam bidang komputer pun semakin meningkat. Dalam pembelajaran, computer sudah menjadi alat bantu yang lazim digunakan dalam berbagai tingkatan sekolah. Software software computer untuk menyelesaikan masalah di bidang matematika juga tersedia. Namun, software - software tersebut belum begitu dikenal para guru maupun siswa sehingga pemanfaatannya terhadap proses pembelajaran kurang diterapkan. Jika pemanfaatan software ini sudah begitu dengan dengan kalangan guru maupun siswa, matematika bukan lagi pelajaran yang paling dihindari.

Saat ini, di Kabupaten Tapanuli Selatan khususnya masih sangat minim pemanfaatan media pembelajaran yang menyebabkan anggapan masyarakat (siswa) terhadap pelajaran matematika sangat sulit sampai saat ini sehingga matematika menjadi sebuah beban bagi siswa dalam mempelajarinya. Beberapa Sekolah Menengah SMA/SMK yang ada di Kecamatan Sipirok antara lain adalah SMA Negeri 1 Sipirok, SMA Negeri 1 Arse, SMK Negeri 1 Sipirok, MAN 1 Negeri Sipirok, SMA Negeri 3 Plus Sipirok, SMK Pertanian LMC Arse, SMK Pertanian Arse, SMA Negeri 1 Angkola Timur. Model pembelajaran yang dilaksanakan di Sekolah tersebut selama ini masih bersifat konvensional artinya guru kurang memanfaatkan media pembelajaran yang ada sementara banyak media yang bias dimanfaatkan oleh guru dalam meningkatkan kompetensinya agar siswa lebih tertarik dalam proses pembelajaran. Salah satu penyebabnya adalah para guru belum memiliki pengetahuan bagaimana memanfaatkan media pembelajaran yang ada. Rendahnya pengetahuan dan kurangnya keterampilan mengenai pemanfaatan media pembelajaran ini membuat siswa merasa kurang tertarik dalam proses pembelajaran . Selain itu kemampuan guru dalam memanfaatkan media yang ada akan berhubungan 
terhadap perkembangan ilmu yang dimiliki siswanya sehingga siswa yang dihasilkan oleh gurunya nanti adalah siswa yang memiliki pengetahuan dan keterampilan di bidangnya.

\section{METODE PELAKSANAAN}

Berdasarkan permasalahan yang telah di kemukakan, maka dalam kegiatan
PKM ini metode pelaksanaan yang digunakan adalah metode eksperimental dan pelatihan. Berikut ini metode pelaksanaan yang dilakukan : Kegiatan workshop dilaksanakan di SMA Negeri 1 Sipirok yang dihadiri oleh guru-guru matematika sebanyak 16 .

Tabel 1: Kegiatan workshop

\begin{tabular}{|c|l|c|}
\hline Kegiatan & \multicolumn{1}{|c|}{ Deskripsi Kegiatan } & Waktu \\
\hline $\begin{array}{c}\text { Survey } \\
\text { Lokasi }\end{array}$ & $\begin{array}{l}\text { Meninjau lokasi sekolah sebagai tempat berkumpul } \\
\text { mitra pada saat pelaksanaan Workshop }\end{array}$ & Minggu pertama \\
\hline Tutorial & $\begin{array}{l}\text { Menjelaskan tentang pemanfaatan media } \\
\text { pembelajaran matematika (software geogebra). }\end{array}$ & $\begin{array}{c}\text { Hari pertama } \\
\text { (Minggu kedua) }\end{array}$ \\
\hline Pelatihan & $\begin{array}{l}\text { Pembimbingan Menjelaskan penggunaan media } \\
\text { pembelajaran (software geogebra). }\end{array}$ & $\begin{array}{l}\text { Hari kedua } \\
\text { Seserta mempraktekkan hasil pembuatan bangun } \\
\text { dimensi dua dan tiga }\end{array}$ \\
\hline Evaluasi & $\begin{array}{l}\text { Mempraktekkan kembali penggunaan media } \\
\text { (software geogebra) dalam pembelajaran } \\
\text { matematika }\end{array}$ \\
\hline
\end{tabular}

Dalam rangka pelaksanaan kegiatan ini, salah satu guru (pengurus MGMP Matematika) yang ada di Kabupaten Tapanuli Selatan yaitu sekolah SMA Negeri 1 Sipirok bersedia menyediakan ruangan sebagai tempat pelatihan dan whitebord sebagai alat bantu. Dan karena ketertinggalan yang terjadi maka kami sipelaksana yang menyediakan sarana pendukung lainnya seperti infokus serta dalam hal alat elektronik seperti laptop setiap guru diperkenankan membawa laptop masing-masing. Serta guru juga mendukung dalam menfasilitasi urusan administrasi selama kegiatan ini.

\section{HASIL DAN PEMBAHASAN}

Adapun hasil yang diperoleh dapat ditunjukkan berdasarkan pelaksanaan yang dilakukan dengan pembahasan sebagai berikut:

\section{Hari ke-1}

Kegiatan hari pertama yaitu tim pengabdian masyarakat memotivasi para guru terkait betapa pentingnya teknologi khususnya computer atau laptop sehingga ketika guru akan melakukan proses belajar mengajar dengan menggunakan media pembelajaran yang ada (geogebra). Kegiatan ini dapat dikatakan terlaksana dengan baik hal ini didasari oleh antusias para peserta dalam mengikuti kegiatan. Hal ini dapat ditunjukkan berdasarkan banyaknya pertanyaan dari peserta workshop. Berikut adalah beberapa pertanyaan yang diajukan oleh peserta kepada narasumber/pemateri: 
1) Bagaimana cara menginstal aplikasi geogebra ke laptop?

2) Apa kegunaan aplikasi geogebra dalam pembelajaran matematika?

3) Bagaimana cara mudah agar mahir dalam menggunakan aplikasi geogebra?

4) Apa manfaat aplikasi geogebra dalam pembelajaran matematika?

5) Pada materi apa sajakah geogebra dapat digunakan?

Berdasarkan pertanyaan pertanyaan yang diajukan para peserta pelatihan tersebut maka dapat dikatakan bahwa kegiatan berjalan dengan lancar sesuai yang diharapkan, menambah informasi dan pengetahuan bagi peserta ini didasari karena antusias peserta dalam mengikuti persentase dari awal sampai akhir kegiatan.

\section{Hari ke-2 dan ke-3}

Kegiatan pelatihan pada hari ke dua ini adalah membahas materi yang ada dalam pembelajaran matematika dimana guru - guru melakukan praktek langsung dengan laptop masingmasing. Berdasarkan hasil pengamatan dan hasil pelaksanaan maka kegiatan pelatihan ini memberikan hal-hal yang baru bagi para peserta pelatihan dan sekaligus memberikan manfaat yang besar untuk membantu guru dalam memudahkan pembelajaran matematika, dimana sebelumnya para peserta belum pernah diberikan seminar/pelatihan bagaimana memanfaatkan geogebra dalam pembelajaran matematika. Kegiatan ini dapat dikatakan berhasil dan terlaksana hal ini juga di dasarkan pada antusias para peserta mengikuti kegiatan dan antusias dalam mengajukan pertanyaan. Berikut adalah pertanyaan-pertanyaan yang diajukan para peserta:

1) Bagaimana cara kita mencopy document dari aplikasi geogebra ke document?
2) Bagaimana membuat grafik pada aplikasi geogebra?

3) Bagaimana konsep pembuatan geogebra terhadap materi pelajaran matematika?

4) Bagaimana menyelesaikan persamaan matematika pada aplikasi geogebra?

5) Apakah ada cara cepat dalam menguasai aplikasi geogebra?

6) Apakah dalam setiap materi pelajaran yang ada dalam matematika memiliki cara yang berbeda dalam geogebra?

Berdasarkan pengamatan terhadap pertanyaan-pertanyaan yang diajukan oleh para peserta terlihat bahwa para peserta sudah memiliki gambaran terkait kinerja yang akan dibuat. Peserta pelatihan juga antusian mengikuti jalannya kegiatan pelatihan ini dapat dilihat dari banyaknya peserta yang merespon/bertanya terkait materi yang disajikan. Berdasarkan jenis pertanyaan yang diajukan maka dapat disimpulkan bahwa para peserta sudah banyak memiliki informasi terkait geogebra sehingga kegiatan yang dilaksanakan dapat terlaksana sesuai yang diharapkan.

\section{Hari ke 4 dan ke-5}

Kegiatan workshop pada hari ke empat dan kelima ini merupakan puncak dari kegiatan workshop karena pada hari keempat dan kelima kegiatan yang dilakukan adalah demo peserta terkait dengan pemanfaatan aplikasi geogebra ini. Presentasi disampaikan dengan beberapa materi yang terdapat dalam matematika. Materi pertama yang disampaikan adalah persamaan linear, materi kedua adalah pertidaksamaan linear dan materi yang ketiga adalah bentuk akar dan eksponen. Kegiatan ini dapat dikatakan berhasil dan terlaksana didasarkan pada antusias para peserta mengikuti kegiatan dan 
Nur Sahara, dkk. Workshop Pemanfaatn Media Pembelajaran Geogebra...

antusias dalam melakukan presentasi dari setiap materi yang telah diberi pelatihan.

\section{KESIMPULAN}

Berdasarkan hasil kegiatan workshop yang sudah dilakukan, maka diperoleh kesimpulan yaitu diperoleh feedbac yang positif dari pihak sekolah, dan guru-guru MGMP Matematika di Tapanuli Selatan selama mengikuti kegiatan workshop. Bertambahnya informasi, pengetahuan, dan pemahaman guru-guru di Tapanuli Selatan terkait penggunaan aplikasi geogebra dalam pembelajaran matematika. Tingginya motivasi yang dimiliki oleh guru-guru MGMP Matematika Tapanuli Selatan dalam mengikuti kegiatan workshop.

\section{UCAPAN TERIMA KASIH}

Terima kasih kepada Universitas Muhammadiyah Tapanuli Selatan yang telah memberikan Dana hibah skim Pengabdian Kepada Masyarakat tahun anggaran 2017-2018.

\section{DAFTAR PUSTAKA}

Geogebra Manual The Official manual of Geogebra, http;//code.pedia press.com/, 2011

Kusumah, Yaya S. 2003. Desain dan Pengembangan Bahan Ajar Matematika Interaktif Berbasiskan Tekhnologi Komputer. Makalah Terdapat pada Seminar Proceeding National Seminar on Science and Math Education diselenggarakan oleh FMIPA UPI Bandung bekerja sama dengan JICA

Marfuah 2013. Geogebra untuk Pembelajaran Matematika, Diklat Online 2013, PPPPTK Matematika Yogyakarta

Moch, Fatkoer Rohman, Panduan Penggunaan GeoGebra Software Alat Bantu Pembelajaran Matematika, http;//www.mathzone.web.id.

Muh, Tamimuddin $\mathrm{H}$ dan Muda Nurul Khikmawati, Pemanfaatan TIK dalam Pembelajaran Matematika Pemanfaatan Software Aplikasi Geogebra, Diklat Online e-Training PPPPTK Matematika Yogyakarta. 